\title{
Motor root conduction in neuralgic amyotrophy: evidence of proximal conduction block
}

\author{
Yew-Long Lo, Kerry R Mills
}

\begin{abstract}
Objective-To determine the presence and role of proximal conduction block in neuralgic amyotrophy.

Methods-Percutaneous electrical stimulation of cervical roots and brachial plexus was employed in eight patients with neuralgic amyotrophy. Root to Erb's point compound muscle action potential amplitude ratios for abductor digiti minimi, extensor digitorum communis, biceps, and deltoid muscles were compared with results obtained from 10 healthy controls. Results-Conduction block in the nerve to one muscle was found in three of eight patients $(38 \%)$ suggesting focal proximal demyelination. Repeat studies showed axonal degeneration, resolution, and persistence of conduction block in these three patients respectively.

Conclusion-Focal conduction block plays a significant part in the pathogenesis of neuralgic amyotrophy, which is generally regarded as an axon loss process. Therapeutic intervention should be directed to patients with persistent conduction block, with the aim of eradicating the block and possibly minimising subsequent axon loss. (F Neurol Neurosurg Psychiatry 1999;66:586-590)
\end{abstract}

Keywords: neuralgic amyotrophy; proximal stimulation; conduction block

Neuralgic amyotrophy, otherwise known as the Parsonage-Turner syndrome, ${ }^{1}$ idiopathic brachial plexopathy, or brachial neuritis, ${ }^{2}$ refers to a well defined clinical syndrome having documented precipitating factors and possible aetiologies. ${ }^{3}$ Severe pain of rapid onset around the shoulder region is usually the initial symptom, often persisting for days to weeks. ${ }^{4}$ This is followed by weakness and wasting of shoulder girdle and upper limb muscles, which become prominent features as the pain begins to subside. $^{5}$ The distribution of weakness is variable, although muscles around the shoulder girdle are most commonly involved. ${ }^{6-8}$ Sensory symptoms are not marked, ${ }^{4}$ but may occur in a root or nerve distribution. Lesions in a peripheral nerve distribution rather than a patchy plexopathy may occur. ${ }^{9}$ Cases with involvement of the sternomastoid or diaphragm have also been described, and familial ${ }^{10-12}$ and recurrent cases ${ }^{513-15}$ are encountered.

Although the clinical entity has long been recognised, little is known of its aetiology. An immune mediated or allergic process has been suggested on the basis of its association with infections, ${ }^{5}$ but other well documented precipi- tating factors such as childbirth, ${ }^{16}{ }^{17}$ trauma, and surgery ${ }^{18-20}$ create difficulty in proposing a unified pathogenetic mechanism. Neurophysiologically, neuralgic amyotrophy usually has features of an axonopathy, ${ }^{21}$ but several reported cases, often with atypical clinical features, show evidence suggestive of nerve fibre demyelination. ${ }^{22}$ It has also been suggested that neuralgic amyotrophy, may represent a variant of chronic inflammatory demyelinating polyneuropathy. ${ }^{24}$

Most neurophysiological studies in this condition have been performed on distal nerve segments, which are not helpful in the localisation of proximally situated focal lesions. ${ }^{24}$ Essentially, neurophysiological investigation relies on the demonstration of neurogenic changes in a patchy distribution by EMG. In this study, we have employed proximal nerve stimulation of the cervical roots and the brachial plexus to investigate for the first time proximal motor conduction in neuralgic amyotrophy. We find that in most cases the lesion is axonal degeneration in nature, but in some there is evidence of proximal conduction block.

\section{Methods}

PATIENTS AND HEALTHY CONTROLS

Patients presenting with sudden onset of shoulder pain followed up to 4 weeks later by weakness of upper limb muscles were included in the study. Patients with possible cervical radiculopathy, sensorimotor neuropathy secondary to systemic conditions, local trauma, and anterior horn cell disease were excluded. Of an original group of 14 patients presenting with suggestive features, six were excluded for these reasons. Over a period of 11 months, eight patients (including one woman) were recruited. In addition, 10 healthy controls were studied using identical techniques. All gave their informed consent and were free from any neurological conditions. Their ages ranged from 27 to 51 years. The interval between the onset of symptoms to the time of study ranged from 2 weeks to 8 months.

NERVE CONDUCTION STUDIES AND EMG

All patients had peripheral nerve conduction studies, including median and ulnar sensory studies, median and ulnar motor conduction, and minimal $\mathrm{F}$ wave latency using conventional techniques. Needle EMG was performed as clinically indicated.

MOTOR ROOT AND ERB'S POINT STIMULATION This was provided by a high voltage electrical stimulator (Digitimer Ltd, Hertfordshire, England) producing a peak output voltage of 750 
Table 1 Clinical features of patients

\begin{tabular}{llllllll}
\hline Patient & Age & Sex & $\begin{array}{l}\text { Interval } \\
\text { (months) }\end{array}$ & $\begin{array}{l}\text { Shoulder } \\
\text { pain }\end{array}$ & $\begin{array}{l}\text { Duration } \\
\text { (weeks) }\end{array}$ & $\begin{array}{l}\text { Family } \\
\text { history }\end{array}$ & Patient history \\
\hline 1 & 29 & $\mathrm{M}$ & 2.0 & $\mathrm{R}$ & 2 & - & - \\
2 & 67 & $\mathrm{M}$ & 8.0 & $\mathrm{R}$ & 3 & - & - \\
3 & 51 & $\mathrm{M}$ & 1.5 & $\mathrm{R}$ & 3 & - & - \\
4 & 68 & $\mathrm{M}$ & 1.0 & $\mathrm{~L}$ & 3 & + & - \\
5 & 48 & $\mathrm{M}$ & 2.0 & $\mathrm{R}, \mathrm{L}$ & 3 & - & - \\
6 & 62 & $\mathrm{M}$ & 2.0 & $\mathrm{R}$ & 4 & - & $\mathrm{R}$ side 2 years ago \\
7 & 37 & $\mathrm{~F}$ & 2.5 & $\mathrm{~L}$ & 2 & - & $\mathrm{R}$ side 9 years ago \\
8 & 58 & $\mathrm{M}$ & 0.5 & $\mathrm{R}$ & 2 & - & - \\
\hline
\end{tabular}

$\mathrm{R}=$ Right; $\mathrm{L}=$ left. Interval refers to the time in months from the onset of symptoms to the initial examination and neurophysiological study. Duration refers to the duration of shoulder pain Patient 4 had two affected siblings. Patient 5 had salmonella enteritis 1 week before onset. Patient 7 had a caesarean delivery 3 weeks before onset. Patient 8 had a 20 year history of limb girdle dystrophy.

V. To achieve maximal stimulation, $14 \mathrm{~mm}$ diameter surface electrodes with an interelectrode distance of $14 \mathrm{~cm}$ were used. Stimuli with a $5 \mu$ sise time and $100 \mu$ s decay were applied over the cervical vertebral column via silver electrodes covered in saline soaked lint and mounted on a straight plastic holder. The cathode was placed in the midline $e^{25}{ }^{26}$ between the appropriate vertebral spines. With this method, the motor roots are excited $2-4 \mathrm{~cm}$ distal to the anterior horn cell body, corresponding to the exit foramen of the motor root from the spinal column. ${ }^{25}$ Stimulation was performed over the $\mathrm{C} 7 / \mathrm{T} 1$ interspace and moved upwards sequentially for C7, C6, and C5 root stimulation.

Cathodal stimulation at Erb's point was also performed using the same stimulator. It was clearly important to ensure that supramaximal stimulation was delivered at each site. To this end, responses were collected at increasing stimulation intensity, until it was certain that a further increase of at least $10 \%$ beyond maximal stimulation intensity did not produce a larger response.

\section{RECORDING}

Surface recordings were made with electrodes taped over the belly and tendon of the muscle under study. We studied four muscles in each arm to cover innervation by the $\mathrm{C} 5$ to $\mathrm{C} 8$ roots: these were abductor digiti minimi (ADM), extensor digitorium communis (EDC), biceps brachii, and deltoid. Compound muscle action potentials (CMAPs) were amplified, filtered with a bandpass of $3 \mathrm{~Hz}$ to $10 \mathrm{kHz}$ and stored digitally (CED 1401 plus, Cambridge Electronic Design Ltd, Cambridge, England). Onset latency, negative peak amplitude, and negative peak area of CMAPs were measured. The experiences of others ${ }^{27}$ and ourselves are that conduction velocities across the brachial plexus prove difficult to estimate precisely, as the distance between the sites of cervical root and plexus stimulation cannot be measured exactly. Hence, conduction velocities were not calculated between the neck and Erb's point. Repeat studies were performed on three patients $(2,6$, and 8$)$ at intervals of 7 months, 9 months, and 1 month respectively.

\section{Results}

The clinical features of all eight patients are summarised in table 1 . Of the eight patients, five had sensory symptoms, two had recurrent neuralgic amyotrophy, with one on the ipsilateral (patient 6) and one on the contralateral side (patient 7), two gave a history of trauma or infection (patients 5 and 7) and one patient had a positive family history of neuralgic amyotrophy (patient 4$)$. Four patients $(1,2,5$, and 7$)$ showed predominantly upper plexus involvement, three (3, 4, and 8) lower plexopathy, and patient 6 had diffuse abnormalities referable to the upper and lower plexus.

NEUROPHYSIOLOGICAL STUDIES

There was no evidence of a reduced conduction velocity or conduction block in the conventional peripheral motor studies of ulnar and median nerves. Prolongation of $\mathrm{F}$ latencies was not demonstrable in any of the eight patients. CMAPs to both wrist and elbow stimulation were reduced in intrinsic hand muscles in patients $3,4,6$, and 8 and in general, correlated well with the sites of weakness detected on examination. Of the five patients manifesting sensory signs or symptoms, only one showed reduction in ulnar sensory action potential amplitude (patient 5). However, this patient had sensory loss over the lateral forearm.

Abnormal EMG findings seen in all patients were highly concordant with physical signs, with the most significant findings seen in the weakest muscles. It is noteworthy that proximal conduction block was suspected when EMG failed to show active denervation changes in the presence of distinct clinical weakness and minimal wasting. This proved to be the case in patients 6 and 8 .

Table 2 Proximal electrical stimulation CMAP amplitudes $(\mathrm{mV})$

\begin{tabular}{|c|c|c|c|c|c|c|c|c|c|c|c|c|c|c|c|c|}
\hline \multirow[b]{3}{*}{ Patient } & \multicolumn{8}{|l|}{ Right } & \multicolumn{8}{|l|}{ Left } \\
\hline & \multicolumn{2}{|l|}{$A D M$} & \multicolumn{2}{|l|}{$E D C$} & \multicolumn{2}{|c|}{ Biceps } & \multicolumn{2}{|c|}{ Deltoid } & \multicolumn{2}{|c|}{$A D M$} & \multicolumn{2}{|l|}{$E D C$} & \multicolumn{2}{|c|}{ Biceps } & \multicolumn{2}{|c|}{ Deltoid } \\
\hline & $N$ & $E$ & $N$ & $E$ & $N$ & $E$ & $N$ & $E$ & $N$ & $E$ & $N$ & $E$ & $N$ & $E$ & $N$ & $E$ \\
\hline 1 & 10.8 & 11.0 & 15.8 & 17.2 & 28.9 & 24.1 & 15.8 & 20.4 & 8.2 & 9.6 & 9.1 & 9.3 & 22.9 & 24.7 & 17.7 & 20.3 \\
\hline 2 & 5.9 & 5.9 & 3.5 & 3.6 & 5.5 & 5.4 & 2.9 & 7.9 & 8.1 & 8.1 & 6.7 & 6.4 & 17.0 & 17.8 & 14.7 & 15.8 \\
\hline $2 \mathrm{r}$ & - & - & - & - & 6.3 & 6.4 & 3.5 & 4.6 & - & - & - & - & - & - & - & - \\
\hline 3 & 6.0 & 6.7 & 4.0 & 5.8 & 14.4 & 14.4 & 18.6 & 23.1 & 7.4 & 7.8 & 5.1 & 6.1 & 11.3 & 11.7 & 16.0 & 17.7 \\
\hline 4 & 7.9 & 9.9 & 4.7 & 6.3 & 16.0 & 17.3 & 14.0 & 14.3 & 0.4 & 0.4 & 1.4 & 1.8 & 14.3 & 15.8 & 12.0 & 11.5 \\
\hline 5 & 7.8 & 8.0 & 6.6 & 6.7 & 20.0 & 20.0 & 4.5 & 5.0 & 8.9 & 9.4 & 13.6 & 12.1 & 25.0 & 21.5 & 15.0 & 16.2 \\
\hline 6 & 6.5 & 6.5 & 3.2 & 3.8 & 1.2 & 3.1 & 4.6 & 3.0 & 9.6 & 9.9 & 8.7 & 9.1 & 11.6 & 10.6 & 14.8 & 10.4 \\
\hline $6 r$ & 6.5 & 7.4 & 4.1 & 5.1 & 5.0 & 6.2 & 5.5 & 6.5 & - & - & - & - & - & - & - & - \\
\hline 7 & 10.0 & 10.6 & 9.3 & 9.1 & 9.8 & 10.3 & 19.1 & 18.2 & 10.3 & 11.5 & 8.6 & 8.5 & 14.0 & 14.4 & 13.3 & 12.3 \\
\hline 8 & 2.5 & 3.9 & 2.4 & 2.5 & 3.6 & 3.5 & 2.6 & 2.6 & 4.0 & 4.6 & 5.8 & 7.4 & 3.1 & 4.5 & 2.5 & 2.4 \\
\hline $8 r$ & 1.4 & 2.3 & 2.0 & 2.2 & 3.5 & 3.5 & 2.8 & 2.8 & - & - & - & - & - & - & - & - \\
\hline
\end{tabular}



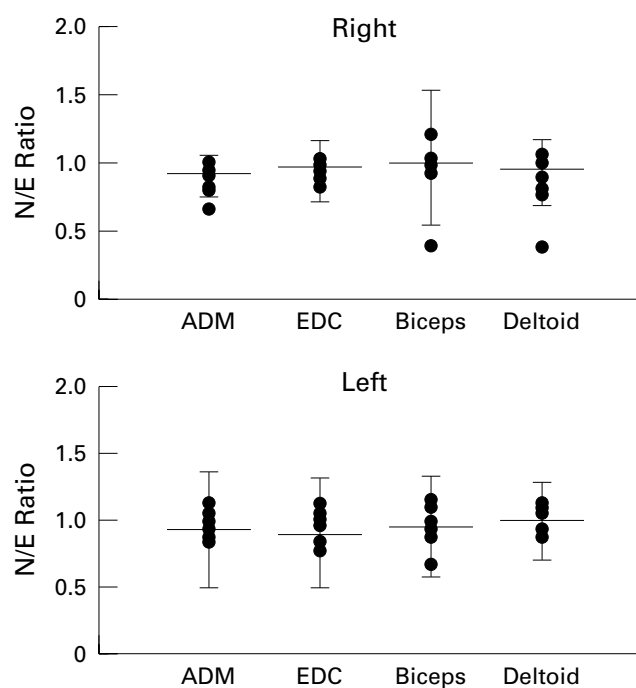

Figure 1 Neck to Erb's point (N/E) CMAP amplitude ratios of all four muscles with electrical stimulation. Filled circles denote N/E ratios for each muscle in individual patients. Error bars denote 2 SDs above and below the mean N/E ratios of controls. The long central line between error bars denotes the mean N/E ratio of controls for each muscle. Conduction blocks were evident in the right abductor digiti minimi (ADM) for patient 8 , right biceps brachii for patient 6, and right deltoid for patient 2 . $E D C=$ extensor digitorium communis.
PROXIMAL STIMULATION

The results are summarised in table 2 and figs 1 and 2 . All patients studied tolerated the procedure well. Conduction block was defined as a root to Erb's CMAP amplitude ratio less than 2 $\mathrm{SD}$ of the healthy controls' values for each muscle. Control mean (SD) ratio values for the right $\mathrm{ADM}, \mathrm{EDC}$, biceps brachii, and deltoid were 0.93 (0.05), 0.93 (0.08), 1.04 (0.24), and 0.95 (0.09) respectively. The corresponding values for the left side were $0.94(0.19), 0.91$ (0.17), $0.94(0.16)$, and $0.96(0.13)$. Conduction block between root exit foramina and Erb's point was demonstrable in three patients $(2,6$, and 8$)$, who exhibited ratios of $0.37,0.39$, and 0.64 in the right deltoid, biceps, and abductor digiti minimi respectively. Ratios of the negative peak areas of CMAPs were also considered and identified the same three patients as having significant conduction block. With the exception of patient 1 , who had no motor conduction abnormality, all other patients had small CMAPs from both root and Erb's point stimulation, indicating an underlying loss of axons.

Repeat studies on the three patients with conduction block at various intervals after the initial study yielded additional information on disease progression. In patient 2 , the conduction block seen in the right deltoid gave way to an axon loss lesion with reduction of CMAP amplitudes from both root and Erb's point stimulation. The initial conduction block in the right biceps in patient 6 disappeared with increase of CMAP amplitudes evoked from root and Erb's stimulation and a ratio increasing to normal. However, this was not the case in patient 8 , whose repeat study showed increased conduction block from 0.64 to 0.61 in the right $\mathrm{ADM}$.

\section{Discussion}

The presence of conduction block is well documented in acute or chronic demyelinating polyneuropathy ${ }^{28}$ and multifocal motor neuropathy with conduction block. ${ }^{29}$ However, focal conduction block, particularly in the most proximal motor root segments, has not been shown previously in neuralgic amyotrophy. Most existing studies employed conventional techniques, which are not helpful in localising proximal lesions precisely. In our experience and others, ${ }^{21}{ }^{30} \mathrm{~F}$ waves were not useful in this respect; presumably surviving or unblocked axons are able to generate an $\mathrm{F}$ response at the normal latency. Needle EMG is useful in identifying active denervation changes, and paraspinal muscle sampling with its inherent disadvantages of technical difficulty and myotomal overlap only localises the lesion proximal or distal to the posterior primary rami. ${ }^{31} \mathrm{By}$ contrast, we find percutaneous electrical root stimulation a useful, well tolerated test for localising motor root diseases.

Clinical and neurophysiological evolution of the three patients in which conduction block was demonstrated is of some interest. Patient 2 presented with a typical history of neuralgic amyotrophy with no obvious precipitating cause. His condition did not improve and when 
seen 8 months later a conduction block was detected recording from the right deltoid. $\mathrm{He}$ had repeat studies 7 months later (15 months after initial presentation) which disclosed findings consistent with an axon loss lesion. Clinically, he did not show improvement in muscle power in his right deltoid, although the distal muscles were considerably stronger. Patient 6 had a previous episode of neuralgic amyotrophy which recovered completely 2 years before this recurrent episode. His initial studies performed 2 months after onset showed a conduction block in the right biceps brachii. Repeat studies 9 months later (11 months after the recurrent presentation) showed resolution of the block and improved CMAP amplitudes. Clinically, he had significant improvement in power of both proximal and distal muscles. Patient 8 presented with typical symptoms of neuralgic amyotrophy, again with no obvious precipitating cause. He had a 20 year history of limb girdle muscular dystrophy confirmed on biopsy, with minimal functional deficit. Initial studies within 2 weeks of onset of his symptoms showed a conduction block recording from the right ADM, the weakest muscle. Repeat studies 1 month later (6 weeks after initial presentation) showed further reduction of CMAP amplitudes and persisting conduction block. $\mathrm{He}$ did not experience any clinical improvement in muscle power.

It should be pointed out, however, that many peripheral nerve disorders are characterised by a mixture of demyelinating and axonal degeneration features. Few cases of neuropathy in general fall precisely into pure axonal or demyelinating categories. ${ }^{32}$ A neuropathy from extensive demyelination is often associated with axonal degeneration. ${ }^{33-36}$ Conversely, axonal neuropathy may lead to secondary paranodal demyelination. ${ }^{37}$ Whereas it is well known that the distal portion of a sectioned nerve undergoes secondary demyelination as a result of axonal degeneration, ${ }^{38}$ the mechanism of paranodal segmental demyelination from localised changes or diffuse metabolic insults is less well understood. Various postulates have been put forward, ranging from hypotheses akin to pre-wallerian degeneration mechanisms ${ }^{39}$ to local processes causing a reduction in volume of the axon cylinder with disturbed ultrastructure of transport organelles. ${ }^{40}{ }^{41}$ It is therefore appropriate to consider whether demyelinating or axon loss processes coexisted or if one preceded the other.

Pathological studies favour an immune mediated demyelinating pathogenesis over an axon loss mechanism in neuralgic amyotrophy. Sierra et al reported decreased CD3 and CD8 lymphocyte subsets in five of six patients with acute neuralgic amyotrophy. ${ }^{22}$ Nerve biopsies of a patient with relapsing brachial plexus neuropathy and bilateral upper trunk conduction block showed florid multifocal mononuclear inflammatory plexus infiltrates. ${ }^{42} \mathrm{~A}$ postmortem based study showed widespread demyelination. ${ }^{43} \mathrm{~A}$ focal immune mediated mechanism of demyelination has been postulated in interleukin-2 associated brachial plexopathy. ${ }^{44}$ Immune complex formation has also been implicated as a cause of acute brachial plexus neuropathy and the GuillainBarré syndrome associated with serum sickness. ${ }^{45}$ It is known that antiperipheral nerve myelin antibodies are associated with demyelination in Guillain-Barré syndrome. ${ }^{46-48}$ Vriesendrop et al showed that these antibodies and soluble terminal activation products were increased in the acute phase of neuralgic amyotrophy and decreased subsequently during clinical recovery. ${ }^{23}$ They concluded that complement dependent antibody mediated demyelination may participate in the initial phase of nerve damage or augment an ongoing process. By contrast, there remains minimal evidence to date favouring acute axonal destruction in response to a direct or indirect immunological insult, ${ }^{49}$ as seen in a few cases of axonal Guillain-Barré syndrome established by postmortem examination.

It can be deduced from our clinical and electrophysiological findings that although neuralgic amyotrophy is thought to be a condition predominantly characterised by axon loss, focal demyelination may play a significant part in its pathogenesis. Focal demyelination manifesting as conduction block may be detected as early as 2 weeks after the onset of the condition (patient 2 ) in the clinically most affected muscle. From here, the condition may takes two courses: resolution of conduction block with clinical improvement (patient 6) or progression to axonal degeneration with protracted clinical deficit (patient 2). It is possible that conduction blocks could be detected in more muscles if proximal stimulation studies were performed closer to the time of initial presentation. Hence, it is logical that therapeutic interventions should be directed to the group of patients showing electrophysiologically confirmed conduction block, with the aim of eradicating the block and possibly minimising subsequent axonal degeneration.

Most studies on neuralgic amyotrophy have described it is as a self limiting condition with a good prognosis. In general, it is noted that $80 \%$ to $90 \%$ of patients would be expected to recover by 3 years, ${ }^{5}$ leaving $10 \%$ to $20 \%$ with considerable residual muscle weakness. There are several reports, however, of less favourable outcomes. ${ }^{50-52}$ A retrospective evaluation of 44 patients 1 to 7 years after the illness onset showed that 32 still had objective deficits and 17 experiencing intermittent complaints of radicular origins, particularly in patients with jobs of a manual nature. ${ }^{53}$ Recovery can begin very late in the illness, sometimes up to 6 months. ${ }^{54}$ With early and severe muscle wasting, the prospect of useful power returning can be poor. ${ }^{1}$ These cases are especially prone to late complications of scapulocostal pain syndromes, which can leave the patient with considerable morbidity. ${ }^{55}$ It might therefore be justifiable to identify these cases early with a view to therapeutic intervention such as intravenous immunoglobulin, which has been shown to be useful in other focal demyelinating diseases of the peripheral nerve. ${ }^{28}{ }^{29}$ 
1 Parsonage MJ, Turner JWA. Neuralgic amyotrophy: the shoulder-girdle syndrome. Lancet 1948;i:973-8.

2 Tsairis P Brachial plexus neuropathies. In: Dyck PJ, Thomas PK, Lambert EH, eds. Peripheral neuropathy. 1st ed Philadelphia: WB Saunders 1975:669-71.

3 Magee KR, DeJong RN. Paralytic brachial neuritis. $\mathscr{F} A M A$ 1960;174:1258-62

4 England JD, Sumner AJ. Neuralgic amyotrophy: an increasingly diverse entity. Muscle Nerve 1987;10:60-8.

5 Tsairis P, Dyck PJ, Mulder DW. Natural history of brachial plexus neuropathy. Arch Neurol 1972;27:109-17.

6 James JL, Miles DW. Neuralgic amyotrophy: a clinical and electromyographic study. BMF 1966;2:1042-3.

7 Kennedy WR, Resch JA. Paralytic brachial neuritis. Lancet 1966;86:459-62.

8 Weikers NJ, Mattson RH. Acute paralytic brachial neuritis. A clinical and electrodiagnostic study. Neurology 1969;19: 1153-8.

9 Rennels GD, Ochoa J. Neuralgic amyotrophy manifesting as anterior interosseous nerve palsy. Muscle Nerve 1980;3: $160-4$

10 Arts WF, Busch HF, Van den Brand HJ, et al. Hereditary neuralgic amyotrophy. Clinical, genetic, electrophysiological, and histopathological studies. I Neurol Sci 1983;62 261-79

11 Windebank AJ, Schenone A, Dewald GW. Hereditary neuropathy with liability to pressure palsies and inherited brachial plexus neuropathy - two genetically distinct disorders. Mayo Clin Proc 1995;70:743-6.

12 Wehnert M, Timmerman V, Spoelders P, et al. Further evidence supporting linkage of hereditary neuralgic amyotrophy to chromosome 17q. Neurology 1997;48:1719-21.

13 Bradley WG, Madrid R, Thrush DC, et al. Recurrent brachial plexus neuropathy. Brain 1975;98:381-98.

14 Devathasan G, Tong HI. Neuralgic amyotrophy: criteria for diagnosis and a clinical and electromyographic study of 21 cases. Aust N Z f Med 1980;10:188-91.

15 Michotte A, Dierckx R, Deleu D, et al. Recurrent forms of sporadic brachial plexus neuropathy. A report of two cases. sporadic brachial plexus neuropathy.
Clin Neurol Neurosurg 1988;90:71-4.

16 Dimitru D, Liles RA. Postpartum idiopathic brachial neuritis. Obstet Gynecol 1989;73:473-5.

17 Lederman RJ, Wilbourn AJ. Postpartum neuralgic amyotroLermarology 1996;47:1213-9.

18 phy. Neurology 1996;47:1213-9. Dyck PJ, Thomas PK, Lambert EH, et al, eds. Perpheral neuropathy. 2nd ed. Philadelphia: WB Saunders, 1984: 1656-99

19 Malamut R, Marques W, England J. Postsurgical idiopathic brachial neuritis (IBN). Muscle Nerve 1990;13:881-2.

20 Faust JA Jr, Wilson NE. Cesarean section in a patient with unilateral diaphragmatic paralysis, brachial neuritis and pregnancy-induced hypertension. Anesth Analg 1992;75: $622-5$.

21 Flaggman PD, Kelly JJ. Brachial plexus neuropathy: an electrophysiologic evaluation. Arch Neurol 1980;37:160-4.

22 Sierra A, Prat J, Bas J, et al. Blood lymphocytes are sensitized to brachial plexus nerves in patients with neuralgic to brachial plexus nerves in patients with

23 Vriesendorp FJ, Dytrenko GS, Dietrich T, et al Antiperipheral nerve myelin antibodies and terminal activation peripheral nerve myelin antibodies and terminal activation products of complement in serum of patients with acute
brachial plexus neuropathy. Arch Neurol 1993;50:1301-3.

24 Amato AA, Jackson CE, Kim JY, et al. Chronic relapsing brachial plexus neuropathy with persistent conduction block. Muscle Nerve 1997;20:1303-7.

25 Mills KR, Murray NMF. Electrical stimulation over the human vertebral column: which neural elements are excited? Electroenceph Clin Neurophysiol 1986;63:582-9.

26 Schmid UD, Walker G, Hess CW, et al. Magnetic and electrical stimulation of cervical motor roots: technique, site and mechanisms of excitation. 7 Neurol Neurosurg Psychiatry 1990;53:770-7.

27 Jaspert A, Claus D, Grehl H, et al. Wertigkeit der proximalen Leitungsblockuntersuchung in der diagnostik entzündlicher neuropathi. Nervenarzt 1995;66:445-54.

28 Menkes DL, Hood DC, Ballesteros RA, et al. Root stimulation improves the detection of acquired demyelinating polyneuropathies. Muscle Nerve 1998;21:298-308.
29 Jaspert A, Claus D, Grehl H, et al. Multifocal motor neuropathy: clinical and electrophysiological findings. $\mathcal{F}$ Neurol 1996;243:684-92.

30 Kimura J. Clinical value and limitations of $\mathrm{F}$ wave determination. A comment [letter]. Muscle Nerve 1978;1:250-1.

31 Bufalini C, Pescatori G. Posterior cervical electromyography in the diagnosis and prognosis of brachial plexus injuries. $f$ Bone foint Surg 1969;51:627-31.

32 Kimura J. Electrodiagnosis in diseases of nerve and muscle: principles and practice. Philadelphia: FA Davis, 1983:75-6.

33 Gilliatt RW. Nerve conduction in human and experimental neuropathies. Proc R Soc Med 1966:59:989-92.

34 Dyck PJ, Gutrecht JA, Bastron JA, et al. Histologic and teased-fibre measurements of sural nerve in disorders of ower motor and primary sensory neurons. Mayo Clin Proc 1968;43:81-123.

35 Thomas PK. The morphological basis for alterations in nerve conduction in peripheral neuropathy. $\operatorname{Proc} R$ Soc Med 1971;64:295-61.

36 Gilliatt RW. Recent advances in the pathophysiology of nerve conduction. In: Desmedt JE, ed. New developments in electromyography and clinical neurophysiology. Vol 2. Basel: Karger, 1973:2-18.

37 Hopkins A. Toxic neuropathy due to industrial agents. In: Dyck PJ, Thomas PK, Lambert EH, eds. Perpheral neuropathy. Philadelphia: WB Saunders, 1975:1207-26.

38 Norton WT. Chemical pathology of diseases involving myelin. In: Morell P, ed. Myelin. New York: Plenum Press, 1977:384-5.

39 Gombault $M$. Contribution a l'étude anatomique de la névrite parenchymateuse subaiguë et chronique: névrite nevrite parenchymateuse subaigue et chronique: névrite

40 Collins $\mathrm{GH}$, Webster $\mathrm{H}$ deF, Victor $\mathrm{M}$. The ultrastructure of myelin and axonal alterations in sciatic nerves of thiamine deficient and chronically starved rats. Acta Neuropathol (Berl) 1964;3:511-3

41 Dyck PJ, Johnson WJ, Lambert EH, et al. Segmental demyelination secondary to axonal degeneration in uremic neuropathy. Mayo Clin Proc 1971;46:400-31.

42 Suarez GA, Giannini C, Bosch EP, et al. Immune brachial plexus neuropathy: suggestive evidence for an inflammatory-immune pathogenesis. Neurology 1996;46: 559-61.

43 Joffroy A. De la névrite parenchymateuse spontanée généralisée ou partielle. Arch Physiol 1879;6:172-98.

44 Loh FL, Herskovitz S, Berger AR, et al. Brachial plexopathy associated with interleukin-2 therapy. Neurology 1992;42: 462-3.

45 Iqbal A, Arnason BGW. Neuropathy of serum sickness. In: meuropathy 2nd ed. Philadelphia: WB Saunders 1984. 2044-9.

46 Koski CL, Gratz E, Sutherland J, et al. Clinical correlation with anti-peripheral nerve myelin antibodies in the Guillain-Barré syndrome. Ann Neurol 1986;19:573-7.

47 Koski CL, Sanders ME, Svoveland PT, et al. Activation of terminal components of complement in patients with Guillain-Barré syndrome and other demyelinating neuropathies. F Clin Invest 1987;80:1492-7.

48 Vriesendorp FJ, Mayer RF, Koski CL. Kinetics of anti-peripheral nerve myelin antibody in patients with Guillain-Barre syndrome treated and not treated with plasmapheresis. Arch Neurol 1991;48:858-61.

49 Bolton CF. The changing concepts of Guillain-Barré syndrome. N Engl f Med 1995;333:1415-7.

50 Spillane JD. Localised neuritis of the shoulder girdle: a report of 46 cases in the MEF. Lancet 1943;ii:532-5.

1 Turner JWA. Acute brachial radiculitis. BMF 1944;2:592-4.

2 Evans HW. Paralytic brachial neuritis. New York fournal of Medicine 1965;65:2926-8.

53 Huffmann G. Neuralgische schulteramyotrophie, klinik und verlauf. Zeitschrift für Neurologie 1973;206:79-83.

54 Dixon GJ, Dick TBS. Acute brachial radiculitis: course and prognosis. Lancet 1945;ii:707-8.

55 Mumenthaler M, Schliack H. Peripheral nerve lesions. New York: Thieme, 1991:195-6. 